\title{
European Respiratory Society guideline on non-CPAP therapies for obstructive sleep apnoea
}

\author{
Winfried Randerath $\mathbb{1}^{1,20}$, Johan Verbraecken $\mathbb{1}^{2,20}$, Christel A.L. de Raaff ${ }^{3}$, Jan Hedner ${ }^{4}$, Simon Herkenrath ${ }^{1}$, \\ Winfried Hohenhorst ${ }^{5}$, Tina Jakob ${ }^{6}$, Oreste Marrone ${ }^{7}$, Marie Marklund ${ }^{8}$, Walter T. McNicholas $\mathbb{1}^{9,10}$, \\ Rebecca L. Morgan $\mathbb{( i l}^{11}$, Jean-Louis Pepin ${ }^{12}$, Sofia Schiza ${ }^{13}$, Nicole Skoetz ${ }^{6}$, Dan Smyth ${ }^{14,15}$, Jörg Steier (i) ${ }^{16}$, \\ Thomy Tonia ${ }^{17}$, Wojciech Trzepizur ${ }^{18}$, Piet-Heijn van Mechelen ${ }^{14}$ and Peter Wijkstra ${ }^{19}$
}

\begin{abstract}
${ }^{1}$ Bethanien Hospital, Clinic of Pneumology and Allergology, Center for Sleep Medicine and Respiratory Care, Institute of Pneumology at the University of Cologne, Solingen, Germany. ${ }^{2}$ Antwerp University Hospital and University of Antwerp, Edegem (Antwerp), Belgium. ${ }^{3}$ Amsterdam UMC, Dept of Surgery, Amsterdam, The Netherlands. ${ }^{4}$ Dept of Sleep Medicine, Respiratory Medicine and Allergology, Sahlgrenska University Hospital, Gothenburg, Sweden. ${ }^{5}$ Alfried Krupp Hospital, Dept of Otolaryngology, Essen, Germany. ${ }^{6}$ Evidencebased Oncology, Dept I of Internal Medicine, Center for Integrated Oncology Aachen Bonn Cologne Dusseldorf, Faculty of Medicine and University Hospital Cologne, University of Cologne, Cologne, Germany. ${ }^{7}$ National Research Council of Italy, Institute for Biomedical Research and Innovation, Palermo, Italy. ${ }^{8}$ Dept of Odontology, Faculty of Medicine, Umeå University, Umeå, Sweden. ${ }^{9}$ School of Medicine, University College Dublin, Dublin, Ireland. ${ }^{10}$ Dept of Respiratory and Sleep Medicine, St Vincent's Hospital Group, Dublin, Ireland. ${ }^{11}$ Faculty of Health Sciences, McMaster University, Hamilton, Ontario, Canada. ${ }^{12}$ EFCR Sleep and Respiration Unit CHU Grenoble, Grenoble, France. ${ }^{13}$ Sleep Disorders Unit, Dept of Respiratory Medicine, Medical School, University of Crete, Greece. ${ }^{14}$ European Lung Foundation, Sheffield, UK. ${ }^{15}$ Sleep Disorder Support Foundation, Dublin, Ireland. ${ }^{16}$ Lane Fox Unit and Sleep Disorders Centre at Guy's \& St Thomas' NHS Foundation Trust, Centre for Human \& Applied Physiological Sciences, King's College London, London, UK. ${ }^{17}$ Institute of Social and Preventive Medicine, University of Bern, Bern, Switzerland. ${ }^{18}$ Dept of Respiratory and Sleep Medicine, Angers University hospital, Angers, France. ${ }^{19}$ Dept of Pulmonary Diseases, University of Groningen, University Medical Center Groningen, Groningen, The Netherlands. ${ }^{20}$ Co-shared first authorship.
\end{abstract}

Corresponding author: Winfried Randerath (randerath@klinik-bethanien.de)

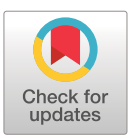

Copyright $\odot$ The authors 202

This version is distributed under the terms of the Creative Commons Attribution NonCommercial Licence 4.0. For commercial reproduction rights and permissions contact permissions@ersnet.org

This article has supplementary material available from err.ersjournals.com

Received: 28 Aug 2021 Accepted: 01 Sept 2021

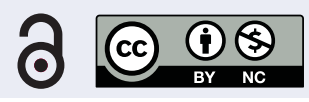

Shareable abstract (@ERSpublications)

OSA-patients who refuse/don't adhere to CPAP can profit from established/emerging treatment options. High scientific evidence is lacking. Patients' values/preference may weigh heavy in the decision for non-CPAP options, while health inequity is a concern. https://bit.ly/3o0tJeP

Cite this article as: Randerath W, Verbraecken J, de Raaff CAL, et al. European Respiratory Society guideline on non-CPAP therapies for obstructive sleep apnoea. Eur Respir Rev 2021; 30: 210200 [DOI: 10.1183/16000617.0200-2021].

\section{Abstract}

Treatment of obstructive sleep apnoea (OSA) in adults is evolving, as new therapies have been explored and introduced in clinical practice, while other approaches have been refined or reconsidered. In this European Respiratory Society (ERS) guideline on non-continuous positive airway pressure (CPAP) therapies for OSA, we present recommendations determined by a systematic review of the literature. It is an update of the 2011 ERS statement on non-CPAP therapies, advanced into a clinical guideline. A multidisciplinary group of experts, including pulmonary, surgical, dentistry and ear-nose-throat specialists, methodologists and patient representatives considered the most relevant clinical questions (for both clinicians and patients) relating to the management of OSA. Eight key clinical questions were generated and a systematic review was conducted to identify published randomised clinical trials that answered these questions. We used the GRADE (Grading of Recommendations Assessment, Development and Evaluation) approach to assess the quality of the evidence and the strength of recommendations. The resulting guideline addresses gastric bypass surgery, custom-made dual-block mandibular advancement devices, hypoglossal nerve stimulation, myofunctional therapy, maxillo-mandibular osteotomy, carbonic anhydrase inhibitors and positional therapy. These recommendations can be used to benchmark quality of care for people with OSA across Europe and to improve outcomes.

\section{Introduction}

Continuous positive airway pressure (CPAP) is the current standard of treatment of obstructive sleep apnoea (OSA), since its description in the early 1980s [1], and is highly effective in suppressing 
respiratory disturbances during sleep as well as improving several patient clinical manifestations [2-8]. However, advances in the pathophysiological understanding of OSA have shown that not only anatomical narrowing of the upper airways, but also impairment of muscle responsiveness, arousability and respiratory drive all contribute to the pharyngeal collapse that is the hallmark of the disorder $[9,10]$.

Furthermore, doubts on the predominant relevance of the number of breathing disturbances during sleep (apnoea-hypopnoea index (AHI)) have been raised based on cluster analysis and outcome data [11]. Although there is evidence that a high number of breathing disturbances (AHI $>30$ events $\cdot \mathrm{h}^{-1}$ ) increases morbidity and mortality of OSA patients, this is less clear for patients with a lower number of breathing disturbances and data on improvement in survival under the well-accepted standard therapy of CPAP are lacking [12-14]. Thus, the importance of patient-related outcomes becomes increasingly important in the indication and selection of OSA therapies $[15,16]$. However, for the time being, the prognostic relevance of high AHI figures does not justify disregard of adequate suppression of breathing disturbances by practitioners. The heterogeneous pathophysiology and the focus on patient-related outcome parameters, in addition to limited positive airway pressure adherence in many patients encourage the search for reliable alternatives to CPAP $[9,10,15,17,18]$. This led to the idea of updating the 2011 European Respiratory Society (ERS) statement on non-CPAP therapies [19] and advancing it to a clinical guideline. In the intervening years, new therapies have been explored and introduced into clinical practice, such as hypoglossal nerve stimulation (HNS) [20, 21]. Other approaches have been refined or reconsidered, such as mandibular advancement or positional therapy [22, 23]. In particular, questions arose on the impact of therapeutic approaches to the function of upper airway muscles, influences on the body position and mandibular position and potential pharmaceutical influences on breathing regulation. Surgical topics address the risk factors of obesity and the facial skeleton, while soft-tissue surgery was omitted due to limited new evidence.

The methodological rules of the ERS for guidelines require limiting the spectrum of investigated techniques and comparisons [24]. Accordingly, the guideline cannot describe the whole field of non-PAP therapies, but focuses on a limited number of clearly defined research questions. The items were selected based on clinical relevance, availability of data and approaches under debate. We excluded topics that are unequivocal components of OSA treatment, such as weight loss in overweight or obese subjects. The therapies were compared to CPAP, other non-PAP therapies or no treatment according to the severity of the disease, the symptoms and availability of alternatives.

\section{Methods}

\section{Task force composition}

The task force was composed of 15 clinician experts from different regions, including pulmonary, surgical, dentistry and ear-nose-throat specialists; four methodologists, two from the ERS and two from an independent academic centre; and two patient representatives, associated with the European Lung Foundation.

\section{Formulation of the topics and questions}

According to the ERS rules, the task force followed the Grading of Recommendations Assessment, Development and Evaluation (GRADE) system to develop a clinical practice guideline. We formulated nine questions, addressing patient, intervention, comparison, outcome (PICO) by telephone conferences. We selected topics that we thought were the most important for patient care (table 1, supplementary tables e2 and e3). The task force considered the 2011 statement on non-CPAP therapies [19] and searched for new developments or substantial new knowledge on previously described therapies. Topics with sufficient description in previous recommendations without new important findings were excluded.

\section{Literature search methods}

We systematically searched the following databases from 1 January 1946 until 15 June 2020: Cochrane Central Register of Controlled Trials (CENTRAL), MEDLINE. The searches were performed by an information specialist. The search strategies for each database are given in the supplementary material. We only included randomised controlled trials (RCTs) and systematic reviews with associated meta-analysis, published in English. These were used as a source to verify sufficient identification of relevant RCTs.

\section{Study selection}

After removal of duplicates, 6307 references were screened for relevance by one clinical expert and one methodologist individually and for every PICO separately. Thus, we used a two-stage process: first, for each PICO question, we screened titles and abstracts independently for whether the population, study design and intervention fitted the specific question. Ineligible references were excluded. In the next step, 
TABLE 1 Patient, intervention, comparison, outcome (PICO) questions

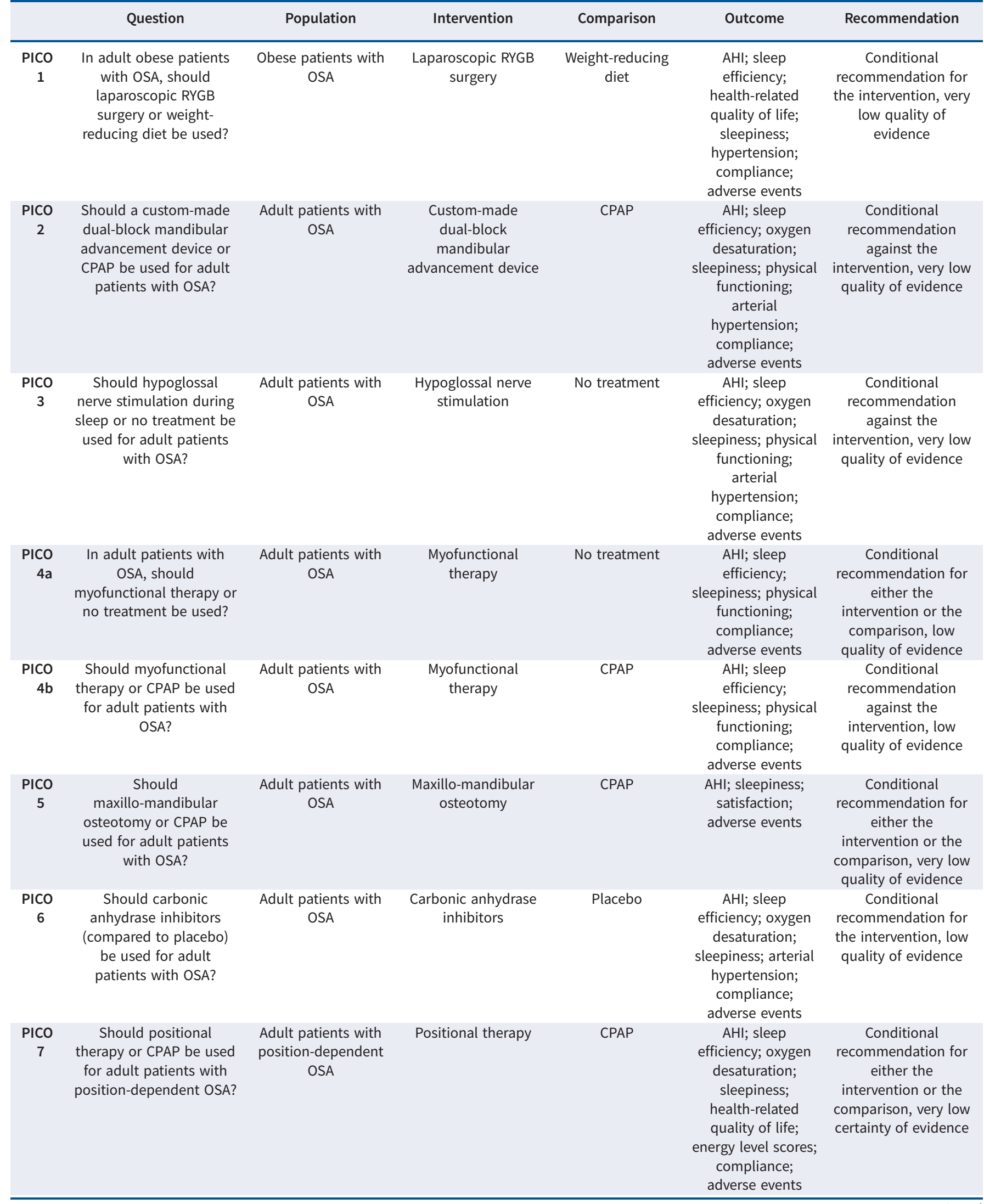


TABLE 1 Continued

\begin{tabular}{|c|c|c|c|c|c|c|}
\hline & Question & Population & Intervention & Comparison & Outcome & Recommendation \\
\hline
\end{tabular}

OSA: obstructive sleep apnoea; RYGB: Roux-en-Y gastric bypass; AHI: apnoea-hypopnoea index; CPAP: continuous positive airway pressure.

we obtained full texts of unclear references or potentially fitting references and assessed independently whether they fitted the PICO question. The methodologists and clinical experts discussed the studies in detail. The experts decided whether studies were homogenous in terms of participants, interventions, comparators and outcome definition. If no consensus on the inclusion was reached between the two, a third task force member was included in the discussion to decide about the relevance of studies. Inclusion criteria were defined according to population, intervention and control of each PICO question. The specific search strategy (supplementary tables e4-e10), the PRISMA diagrams (supplementary figures e1-e7), the meta-analyses (supplementary figures e9-e12) and the findings for each PICO (supplementary figure e8) are presented in the supplementary material.

\section{Evidence syntheses and grading}

For each PICO, data were extracted from the included references for all pre-defined outcomes that were rated as "critical" or "important". All identified studies were judged for risk of bias using the Cochrane Risk of Bias 1.0 tool [25] in duplicate. With this tool we assessed the domain selection bias, performance bias, detection bias, attrition bias, reporting bias and other bias (e.g. cross-over studies reporting overall results only or not taking carry-over effects into account) as being low, unclear or high. Quantitative analysis (meta-analysis) was performed if more than one trial reported data, and the data were homogenous enough. If comparators or interventions differed between trials, separate analyses were performed. If not, results were synthesised narratively. The certainty in the evidence was rated for the body of evidence for outcome individually using the GRADE approach and the appendant software GRADEpro. The reasons for downgrading the certainty of evidence by one to two points are risk of bias, heterogeneity, imprecision, indirectness and potential publication bias [26]. The resulting evidence profiles for each PICO are displayed in the supplementary material.

\section{Assessment of importance of outcomes}

The following outcomes were a priori assessed as critical or important for clinical decision making: AHI (events $\cdot \mathrm{h}^{-1}$ ), sleep efficiency (\%) and $<3 \%$ and $<4 \%$ oxygen desaturation (events $\cdot \mathrm{h}^{-1}$ ), all assessed using polysomnography (PSG); sleepiness assessed using Epworth Sleepiness Scale (ESS); physical functioning assessed using the 36-item short form survey (SF-36) domain; arterial hypertension assessed using $24 \mathrm{~h}$ systolic blood pressure, $24 \mathrm{~h}$ diastolic blood pressure and night-time systolic and diastolic blood pressure; treatment adherence and compliance; and adverse events.

\section{Formulating recommendations}

In two face-to-face meetings in Düsseldorf, Germany (1 July 2019) and Madrid, Spain (1 October 2019), the evidence was presented by the methodologists for each PICO question including the Risk of Bias tool and certainty in the evidence for each outcome. Afterwards, the results were discussed using the GRADE evidence-to-decision frameworks (supplementary tables e11-e19) [26]. After discussing all domains of the evidence-to-decision framework, clear recommendations were formulated by the members of the task force present. Remaining PICOs were discussed in following online meetings following the same approach. The final decisions were performed in an online-consensus meeting on 23 November 2020.

\section{Results}

In total, 41 studies (92 references) were identified through the systematic searches and screening process (supplementary figure e8). 
PICO 1: in adult obese patients with OSA, should laparoscopic Roux-en-Y gastric bypass surgery or weight-reducing diet be used?

Conditional recommendation for the intervention, very low quality of evidence.

Summary of the evidence

For PICO 1, 300 studies were originally identified, and at the end, no direct RCT evidence was found to inform this recommendation (PRISMA diagram: supplementary figure e1, search strategy: supplementary table e4, results: supplementary table e11; no meta-analysis was conducted). However, we decided to use the indirect evidence of an RCT that investigated laparoscopic adjustable gastric banding to make a recommendation. The results of the mentioned trial are discussed here narratively [27, 28].

60 adults with OSA were offered the opportunity to undergo gastric banding versus weight-reducing diet. The mean $\pm \mathrm{sD}$ age of the patients was $47.4 \pm 8.8$ years and $50.0 \pm 8.2$ years, respectively. After the intervention, AHI decreased by 25.5 events $\cdot \mathrm{h}^{-1}$ from 65.0 events $\cdot \mathrm{h}^{-1}$ to 39.5 events $\cdot \mathrm{h}^{-1}$ (95\% CI 14.2 36.7 events $\cdot \mathrm{h}^{-1}$ ), while in the control group, AHI decreased by 14.0 events $\cdot \mathrm{h}^{-1}$ from 57.2 events $\cdot \mathrm{h}^{-1}$ to 43.2 events $\cdot h^{-1}$ (95\% CI 3.3-24.6 events $\left.\cdot h^{-1}\right)$. The difference between the change scores was -11.5 events $\cdot h^{-1}\left(95 \%\right.$ CI $-28.3-5.3$ events $\left.\cdot h^{-1}\right)$, which was not statistically significant $(\mathrm{p}=0.18)$. Sleep efficiency assessed by PSG was 7.4\% higher after gastric banding compared to diet $(\mathrm{p}=0.32)$. Quality of life substantially improved after surgery, based on a 3.5-points higher score on the SF-36 physical scale $(p=0.04)$. The ESS score was 2.4 points lower, but without statistical significance $(p=0.12)$. An effect of surgery on systolic or diastolic blood pressure compared to diet was absent $(\mathrm{p}=0.80$ and $\mathrm{p}=0.37$, respectively). Compliance for the intervention was high, given only four participants did not consent to surgery. Compliance of control treatment was not reported.

\section{Task force recommendation}

In adult obese patients with OSA, we suggest bariatric surgery evaluation versus weight-reducing diet when weight has not improved despite participating in a comprehensive weight reduction programme and if there are no contraindications (conditional recommendation, very low quality of evidence).

Remarks: comorbidities should be considered when making surgical decisions (in favour or against) Patient values and preferences may weigh heavily in their decision for or against surgery (supplementary table e11).

\section{Justification of recommendation}

There was no RCT on Roux-en-Y gastric bypass available in OSA patients. The described study did not exactly match our PICO question (only included gastric banding), so there is only indirect evidence for this PICO. Based on the presented RCT with evidence to use gastric banding surgery as an intervention, the panel determined the benefit to be small, and there were some concerns regarding long-term outcome. Side-effects were considered trivial, since many serious adverse events were not related to the surgical intervention. Given overall weight loss is less after gastric banding than after other bariatric procedures, the panel proposes Roux-en-Y gastric bypass bariatric surgery.

A very low certainty of evidence was given due to concerns about imprecision (only 60 patients included, compliance only described for the intervention arm) and a high risk of bias (unblinded study design and subjectively reported outcomes).

\section{Other considerations}

The intervention is usually acceptable to clinicians, and is mostly acceptable to patients. For health insurers, this depends on the clinical situation. The beneficial outcomes must be balanced against symptoms. In cases of excessive daytime sleepiness or other symptoms, patients may be more willing to accept surgical intervention and related adverse events. In addition, variability could be introduced by age, occupation, severity of the underlying condition and comorbidities. The trial may underestimate the benefit of the intervention, given the study limitations. The panel considered that the overall benefit outweighs the potential harms. For reassessment, a follow-up poly(somno)graphy should be considered 1 year after the intervention. This must be balanced against the weight reduction obtained and dependency on CPAP therapy.

Findings after gastric banding were obtained in morbidly obese patients with severe OSA. The relative change in weight was $26 \%$ after surgery, compared to $4 \%$ after diet, with concomitant change in AHI of $65 \%$ and $32 \%$, respectively (or $-2.5 \%$ AHI per $-1 \%$ weight in surgery and $-8 \%$ AHI per $-1 \%$ weight after diet). This is more or less in line with relative weight changes in overweight patients with milder 
sleep apnoea reported in epidemiological studies. In the Wisconsin sleep cohort [29] it was shown that a relative change in weight of $20 \%$ was associated with a relative change in AHI of $48 \%$ (or $-2.4 \%$ AHI per $-1 \%$ weight), while a relative change in weight of only $5 \%$ was associated with a relative change in AHI of $14 \%$ (or $-2.8 \%$ AHI per $-1 \%$ weight). According to NewmAn et al. [30], this effect is much stronger at a higher Respiratory Disturbance Index and remained much stronger in men than in women. These changes do not guarantee a reduction in OSA severity in all cases. For example, a reduction of 10 events $\cdot \mathrm{h}^{-1}$ in a patient with a starting AHI of 15 events $\cdot \mathrm{h}^{-1}$ reduces the severity class, whereas the same reduction in a patient with 45 events $\cdot \mathrm{h}^{-1}$ does not change the severity class. Nevertheless, cases in the lower severity range can evolve to a non-clinically relevant OSA or can even be cured.

Our recommendation is in agreement with the recent American Thoracic Society recommendation [31], which suggests bariatric surgery over weight-reducing diet (conditional recommendation, very low quality of evidence) for patients with a body mass index (BMI) $\geqslant 35 \mathrm{~kg} \cdot \mathrm{m}^{-2}$. Comorbidities (diabetes, systemic hypertension, cardiovascular disease and orthopaedic problems) should be considered when making surgical decisions for or against this intervention. Patient values and preferences may weigh heavily in their decision for or against surgery.

\section{Suggestions for future research}

More RCTs in adult obese patients with OSA are warranted to demonstrate sustained benefit from surgery and weight-reducing diet on AHI, blood pressure and sleepiness. Compliance to active lifestyle and healthy food intake in this context is paramount.

PICO 2: should a custom-made dual-block mandibular advancement device or CPAP be used for adult patients with OSA?

Conditional recommendation against the intervention, very low quality of evidence.

Summary of the evidence

Dual-block mandibular advancement devices (MADs) are composed of two independent joined parts for the maxilla and mandible. 1334 references were originally identified, and 13 RCTs comparing dual-block adjustable MAD and CPAP therapy were analysed to give this recommendation (supplementary figures e2 and e9, supplementary tables e5 and e12) [22, 32-51]. In total, 597 patients corresponding to 1110 observations were analysed in nine cross-over and four parallel studies. Main analyses were performed in the whole group of patients. Further subgroup analyses were performed according to major inclusion criteria (mild to moderate OSA, moderate to severe OSA, other inclusion criteria) and mean baseline AHI $\left(>30\right.$ events $\cdot h^{-1}$ and $<30$ events $\left.\cdot h^{-1}\right)$. AHI decreased by 7.8 events $\cdot h^{-1}$ (95\% CI 5.5-10.0 events $\cdot h^{-1}$ ) more with CPAP than with MAD among all studied patients. Significant differences in favour of CPAP were found in all severity groups. Sleep efficiency, ESS and quality of life (as assessed by the SF-36 physical scale) did not differ between treatments in the whole group and in all severity subgroups. Four of the 13 studies performed 24-h blood pressure measurements [36, 37, 48, 51] and reported night-time blood pressure. Systolic and diastolic 24-h blood pressure were similar under CPAP and MAD treatments in the whole group and in all severity subgroups. Similarly, no significant differences were found regarding night-time systolic and diastolic blood pressure in the whole group. However, CPAP had a higher impact on night-time systolic blood pressure in moderate to severe OSA patients [37, 51] (mean difference $3.7 \mathrm{mmHg}, 95 \%$ CI $1.3-6.1 \mathrm{mmHg}$ ) and in the study with a mean baseline AHI $>30$ events $\cdot \mathrm{h}^{-1}$ (mean difference $4.2 \mathrm{mmHg}$, 95\% CI 2.2-6.2 mmHg) [37]. Nine studies reported compliance (measured variously). Of these, compliance was better with MAD compared to CPAP in five cases [37, 39, 41, 48, 51]. In the other four cases, no statistically significant difference could be shown or no information on statistics was given [34, 36, 38, 46]. Six studies reported patient preferences. In one study, CPAP was preferred [36]; in the other five, MAD was preferred [39, 40, 48, 50, 51]. Six studies reported adverse events [33, 39-41, 46, 50]. Frequency was described as similar in both groups and intensity was mostly mild.

\section{Task force recommendation}

In adult patients with OSA, we suggest that CPAP should be used as compared to MAD (conditional recommendation, very low quality of evidence).

Remarks: this recommendation does not differentiate according to the severity of the disease. This is because most studies did not focus on specific subgroups in their inclusion criteria. However, most publications presented patients with mild to moderate OSA, and only a minor proportion of severe cases. In mild to moderate OSA, the difference in AHI becomes less important, and therefore, due to equal effects on sleepiness and quality of life, both devices can be considered equally (supplementary table e12). 
Justification of recommendation

This recommendation is mainly based on the higher decrease of the AHI with CPAP over MAD. CPAP has a greater impact on AHI decrease, independently of OSA severity. This consideration, in addition to the higher impact of CPAP on systolic night-time blood pressure decrease in severe OSA, leads the panel to a conditional recommendation in favour of CPAP in patients with OSA. However, in mild and moderate OSA, the AHI under MAD treatment is usually low and close to the normal range. Furthermore, there is some evidence of better compliance and patient preference in favour of MAD as compared to CPAP, and similar impact on sleepiness and quality of life. Altogether, those considerations lead the panel to regard CPAP and MAD as equal in patients with mild to moderate OSA. With increasing severity of OSA, comorbidities or odontological concerns, CPAP should be considered in this group of patients.

\section{Other considerations}

The intervention is usually acceptable to clinicians, patients and health insurers. The availability of MAD treatment might differ between countries due to different healthcare systems, including cost, and different levels of training and interest of dentists in sleep disorders. Indeed, MAD treatment requires coordinated cooperation between dentists and sleep physicians for MAD initiation and long-term follow-up.

\section{Suggestions for future research}

The panel recommend more long-term RCTs with higher numbers of patients, including patients with different levels of OSA severity, various comorbidities and overweight/obesity categories. Investigation of other outcomes than AHI, including cardiovascular and symptom-based outcomes and cost-effectiveness in different European countries are needed. Objective compliance measurements should be preferred to declarative compliance. Studies comparing different types of MAD devices as well as combination therapies (with positional therapy and CPAP) and considerations of oral health, bite changes and changes in pathophysiology with time, such as anatomical and nonanatomical traits related to OSA, are also required.

PICO 3: should HNS during sleep or no treatment be used for adult patients with OSA? Conditional recommendation against the intervention, very low quality of evidence.

\section{Summary of the evidence}

931 references were identified; three different RCTs were identified [20, 52-55], while three other trials were either terminated or ongoing [56-58] (supplementary figure e3, supplementary tables e6 and e13; no meta-analysis was conducted). Two of the studies included invasive HNS, while one study was on transcutaneous HNS. Inconsistency in the study designs and in the reporting of the results (median/mean) meant that no meta-analysis was performed. The AHI and 4\% oxygen desaturation index were assessed using PSG at different follow-up points (range 1 night to 6 months). Two out of three included studies showed no statistical difference between groups at 1 night and 6 months follow-up, while one study showed a statistically significant difference favouring the intervention after 1 week therapy withdrawal in previous responders [20]. Sleep efficiency (percentage of total sleep time) was assessed using PSG (follow-up 1 night) [53]. One study reported sleep efficiency for the 1 night of each intervention and showed no statistically significant difference between arms [53]. None of the studies showed any statistically significant effect for sleepiness. Quality of life was assessed using the Functional Outcomes of Sleep Questionnaire (FOSQ) and Beck Depression Inventory; the follow-up range was 1 week to 6 months. Two studies reported outcomes relating to quality of life (1 week and 6 months follow-up) and both showed statistically significant effects favouring the intervention. One study reported no statistically significant differences between intervention and control looking at systolic and diastolic blood pressure after a week of therapy withdrawal [20]. Compliance/adherence was assessed during follow-up (1 night); only one study reported compliance after the 1 night of treatment [53] (TESLA trial: “The patients' device acceptance was good with patients reporting no skin discomfort or unpleasant sensations at night. There was no difference in patients' perceived sleep quality. There was a 59\% reduction in mouth dryness after active treatment compared to sham-stimulation. There were no severe adverse events”). Adverse events were reported in two studies narratively. The STAR trial reported two serious adverse device-related events and another 33 serious adverse events that were not device-related [20]. Most nonserious adverse events were implantation-related. The TESLA trial (transcutaneous) reported as the only significant side-effect one patient who complained about claustrophobia at night; this was during both nights (intervention and sham-control). The total count of mild side-effects occurred in $2.8 \%$ of the studied cohort and there were no severe adverse events [53]. 
Task force recommendation

We suggest that HNS should not be used as first-line treatment for OSA patients in general (conditional recommendation, very low quality of evidence). However, we suggest that HNS compared to no treatment should be considered as a salvage treatment in patients with symptomatic OSA, who cannot be sufficiently treated with positive airway pressure treatment (CPAP, bilevel positive airway pressure) or MAD, and who have an AHI $<50$ events $\cdot \mathrm{h}^{-1}$ and a BMI $<32 \mathrm{~kg} \cdot \mathrm{m}^{-2}$ (conditional recommendation, very low quality of evidence) (supplementary table e13).

\section{Justification of recommendation}

There is limited evidence available for this intervention; a general recommendation was based on selected patients from three RCTs with very strict patient selection (only $\sim 10 \%$ of the screened patients were included) [20, 52, 53]. The recommendation for a salvage therapy is based on the inclusion criteria and results of the STAR trial [20].

\section{Other considerations}

Additional confirmation of safety and efficacy is now available on HNS in the follow-up cohorts of trials ( $\geqslant 5$ years). Various methods have become available (HNS, targeted, bilateral, transcutaneous) and particular focus should be on the differentiation into invasive versus transcutaneous (noninvasive) procedures. HNS is currently not applied in many countries; except for the noninvasive approach, it remains costly, and a cost-effectiveness analysis in European healthcare systems will be useful. In the United Kingdom, the National Institute for Health and Care Excellence has published an interventional procedural guidance on safety and efficacy, but reimbursement remains unclear. In other countries, like Germany, the method has become available, but is only available to few patients. In a specific group of patients who do not adequately respond to CPAP or MAD and remain sleepy, this method may be beneficial. However, the invasiveness of HNS means that it is not easily reversible. The transcutaneous method is more affordable and is currently undergoing an RCT in the domiciliary setting (TESLA home) [59].

Regular follow-up should be performed, similar to CPAP and other treatments, to demonstrate efficacy.

\section{Suggestions for future research}

The task force recommends further RCTs with CPAP or MAD as control, focused on physiological outcomes, systemic hypertension, metabolic effects and symptomatic improvement.

PICO 4a: in adult patients with OSA, should myofunctional therapy or no treatment be used? Conditional recommendation for either the intervention or the comparison, low quality of evidence.

Summary of the evidence

For PICO 4a and 4b, 634 references were originally identified. Nine RCTs were found [60-69] and six RCTs [60-63, 65-67] were used to answer question 4a (supplementary figures e4 and e10, supplementary tables e7 and e14). The interventions included oropharyngeal exercises, circular breathing and muscle training via electrical stimulation. In these studies, 230 adults with OSA were included, underwent PSG $[60,62,63,66,67]$ or a cardiorespiratory sleep study [64] and were randomised to myofunctional therapy or no treatment (placebo) (supplementary figure e4). The mean age of the patients was similar to controls in all studies. After intervention, the AHI decreased by 8.19 events $\cdot h^{-1}$ (95\% CI 2.11-14.27 events $\cdot h^{-1}$ ), although no data regarding significant differences between groups is available in all studies [63, 67]. Sleep efficiency, assessed in three studies including 121 patients, was $0.06 \%$ lower after therapy compared to placebo (95\% CI 3.67-3.79\%), without statistically significant results between groups [60, 62, 63]. Quality of life was assessed using the FOSQ [66], Quebec Sleep Questionnaire [67] and the functional capacity domain of the SF-36 [60] in three studies including 135 patients. Quality of life was improved only in the myofunctional therapy group in one study [60]. In the other two studies, it was improved in both groups (statistically significant only in one study [66]). The ESS score, assessed in six studies including 230 patients, was 2.71 points lower (95\% CI 0.45-4.97 points), but without statistical significance in all studies $[63,66,67]$. Compliance for the intervention, measured subjectively with diaries or objectively, was assessed in five studies including 135 patients [60,62, 63, 65, 66]. It was relatively high compared to controls, ranging from $63 \%$ to $>85 \%$ in four studies [60, 62, 63, 65], and no difference in one study [66]. Data on adverse events were reported in two studies (82 patients) [65, 66]. One reported no adverse or unexpected events in either group [65] and the other reported erythema (scale of 0 (minimum) to six (maximum): treated patients $0.4 \pm 0.7$, placebo $0.2 \pm 1.0 ; \mathrm{p}<0.05$ ), skin irritation (treated patients $0.7 \pm 1.4$, placebo $0.3 \pm 1.2 ; \mathrm{p}<0.05$ ) and facial pain (treated patients $1.1 \pm 1.8$, placebo $0.3 \pm 1.0 ; \mathrm{p}<0.05$ ), compared to placebo patients [66]. 
Task force recommendation

We do not suggest myofunctional therapy as a standard/regular treatment of OSA, but only for specific cases seeking alternative treatments and who are reluctant to undertake surgical or mechanical strategies (conditional recommendation, low quality of evidence) (supplementary table e14).

\section{Justification of recommendation}

There is limited evidence available for this intervention, based on only six small RCTs. Moreover, this treatment offers only a small and probably temporary advantage over existing treatments and patients might reject other proven effective treatment options. Nevertheless, for many patients seeking for alternative treatment options, it might be an acceptable option for those rejecting more effective treatment options. In this case, regular follow-up should be performed, similar to other treatments, in order to demonstrate efficacy. The therapy is limited by cost, feasibility and missing long-term data.

\section{Other considerations}

There are not enough trained professionals (e.g. speech therapists) and there is a concern regarding adequate training in OSA patients. Furthermore, health insurance might not cover this type of treatment, depending on the healthcare system and reimbursement policies.

Suggestions for future research

More RCTs are warranted involving a larger number of patients and longer treatment periods to determine whether the beneficial effects of myofunctional therapy can be sustained over prolonged periods.

PICO 4b: should myofunctional therapy or CPAP be used for adult patients with OSA?

Conditional recommendation against the intervention, low quality of evidence.

Summary of the evidence

As mentioned earlier, for PICO 4a and 4b, 634 references were originally identified; one RCT (oropharyngeal exercises) was used to inform this recommendation [60] (supplementary figures e4 and e10, supplementary tables e7 and e15). 27 adult patients with OSA were randomised to speech therapy and 27 to CPAP, each for 3 months. Mean age of patients was comparable in both groups. Following the intervention, the AHI decreased significantly in both groups $(\mathrm{p}<0.001)$, while sleep efficiency, as assessed by PSG, showed negligible changes. In addition, the ESS score decreased significantly in both groups (both $\mathrm{p}<0.001$ ). Statistical significance for differences in changes of these three variables between groups was not reported. Quality of life assessed using the SF-36 questionnaire improved in the functional capacity domain in the speech therapy group $(p<0.03)$. Compliance to therapy was $60 \%$ in the speech therapy group (subjective assessment) and 30\% in the CPAP group (objective assessment).

\section{Task force recommendation}

We suggest using CPAP instead of myofunctional therapy for adult patients (conditional recommendation against the intervention, low quality of evidence) (supplementary table e15).

\section{Justification of recommendation}

Currently, limited evidence is available for this intervention based on one RCT only. In this RCT, the panel determined that the benefit of the intervention as compared to CPAP was of similar effect size for sleepiness, but lower for AHI with no statistical tests performed to compare the in-group differences. However, no significant side-effects were reported. The low objective compliance to CPAP could explain the significant, but limited, beneficial effects in the CPAP arm; adequate CPAP adherence, as in standard practice, could even further contribute to the benefits observed. The panel concluded that the comparison group (CPAP) was favoured.

\section{Other considerations}

Specific subcohorts of patients could value several outcomes of the intervention, particularly when they have discontinued CPAP therapy. The intervention has a limited feasibility due to insufficient availability of trained speech therapists who, in addition, often lack experience in managing patients with sleep apnoea. Health insurance might not cover this treatment. It is currently not clear whether, and if so for how long, any interventional treatment effects are maintained.

Suggestions for future research

Long-term studies to evaluate feasibility of long-term treatment by myofunctional therapy and RCTs to explore effects of therapy not only on sleep variables, but also on the natural history of patients with OSA under different treatments are needed. 
PICO 5: should maxillo-mandibular osteotomy or CPAP be used for adult patients with OSA?

Conditional recommendation for either the intervention or the comparison, very low quality of evidence.

Summary of the evidence

1246 references were originally identified, of which one RCT was used to inform this recommendation

[70] (supplementary figure e5, supplementary table e8 and e16; no meta-analysis was conducted). 50 adults with OSA were randomised to maxillo-mandibular osteotomy (MMO) or auto-adjusting positive airway pressure (auto-adjusting CPAP). The mean ages of the patients were $49.1 \pm 9.1$ years and $48.7 \pm 10.7$ years, respectively. 1 year after the intervention, AHI decreased by 48.7 events $\cdot h^{-1}$ (from $56.8 \pm 16.5$ events $\cdot h^{-1}$ to $8.1 \pm 7.0$ events $\cdot h^{-1}$ ), while in the control group it decreased by 44.0 events $\cdot h^{-1}$ (from $50.3 \pm 12.4$ events $\cdot \mathrm{h}^{-1}$ to $6.3 \pm 1.9$ events $\cdot \mathrm{h}^{-1}$ ). The difference between the score changes was not statistically significant $(\mathrm{p}=0.21)$. ESS decreased from $11.6 \pm 2.8$ to $7.7 \pm 1.3$, while in the control group it decreased from $11.2 \pm 2.6$ to $5.9 \pm 1.6$. The difference between the score changes was not statistically significant $(\mathrm{p}=0.20)$. Degree of satisfaction with treatment did not show significant differences between the groups.

Task force recommendation

In adult patients with OSA, the task force suggests using either MMO or CPAP (conditional recommendation, very low quality of evidence) (supplementary table e16).

Justification of recommendation

In the presented RCT, the panel determined differential benefits between MMO and CPAP to be trivial. The age limitation is based on the characteristics of the included patients in the RCT. There are sparse data on adolescents and age groups $>60$ years. Moderate adverse effects were associated with MMO, which could also require additional orthodontic work. Initially, patients may prefer CPAP because it is less invasive than MMO, but some patients may find $\mathrm{MMO}$ an acceptable alternative if they value not using CPAP or have other rationale for facial surgery. Patients who value the potential for adverse events or potential aesthetic concerns more, may find MMO less acceptable. For patients experiencing CPAP failure, MMO is an effective alternative. Altogether, the balance of effects may favour CPAP, but younger people and patients with high AHI may be more likely to accept MMO. Availability and cost may be a problem for MMO.

\section{Other considerations}

The intervention is usually acceptable to clinicians and health insurers, but its acceptability may largely vary among patients. There are age limitations in some countries.

Suggestions for future research

At present, evidence from RCTs is extremely limited. More studies are needed. They should also address aspects that were not considered in the available RCT study, like changes in blood pressure and in objective sleep quality.

PICO 6: should carbonic anhydrase inhibitors (compared to placebo) be used for adult patients with OSA?

Conditional recommendation for the intervention, low quality of evidence.

Summary of the evidence

230 references were identified, of which five studies with seven references were included [71-77] (supplementary figures e6 and e11, supplementary tables e9 and e17). The literature on the use of carbonic anhydrase inhibitors in OSA is limited and dominated by studies on acetazolamide. The dose range in available trials is wide (36-1000 mg) and treatment periods up to 3 months have been described. However, following a stringent review there were only five RCTs left to inform our recommendation. The drugs with a carbonic anhydrase inhibitory activity in these trials include acetazolamide (three studies [72-74, 76]), zonisamide (one study [71]) and topiramate (one study [77]). Two of the trials investigated conditions at high altitude [72-74].

The drug was found to reduce sleep apnoea intensity (AHI) by up to $45 \%$ in unselected groups of patients and sleep studies suggested an improvement of sleep efficiency in nonrandomised or noncontrolled studies. The oxygen desaturation index decreased and oxygenation was improved, while there was no documented effect on the ESS. 
The two high-altitude studies included 49 and 51 patients, respectively [72-74]. At altitude, the nocturnal oxygen saturation was higher with acetazolamide ( $91 \%$ and $88 \%$ ) in one study and by $1-2 \%$ in the other [72-74]. In addition, acetazolamide reduced residual sleep apnoea (in patients on auto-positive airway pressure) and reduced nocturnal transcutaneous carbon dioxide partial pressure. Interestingly, acetazolamide reduced excessive blood pressure increases by $7 \mathrm{mmHg}$ (systolic pressure at $1860 \mathrm{~m}$ ) and $10 \mathrm{mmHg}$ (systolic pressure at $2590 \mathrm{~m}$ ). Blood pressure reductions are also reported in the study on zonisamide (5.7 mmHg; not significant) and $4.3 \mathrm{mmHg}$ (placebo-adjusted trend; not significant) but not studied in the sea-level trial of acetazolamide.

Acetazolamide at altitude was associated with a 15-17-min reduction of subjective insomnia, but the Oxford Sleep Resistance Test and Karolinska Sleepiness Scale scores remained unchanged. Improvement in the Pittsburgh Sleep Quality Index, ESS score and SF-36 were reported after topiramate/phentermine treatment, but part of that effect may be explained by the significant weight reduction in that study [77].

Adverse events included those previously described for this drug class, including paraesthaesia, vertigo and unpleasant taste.

Task force recommendation

We suggest use of carbonic anhydrase inhibitors only in the context of an RCT, as there is no drug in this category with an approved label for OSA (conditional recommendation, low quality of evidence) (supplementary table e17).

\section{Justification of recommendation}

The acute effects of carbonic anhydrase inhibitors in OSA are reasonably well documented and there is biological plausibility, although the amount of evidence is limited. The effect on coincident comorbid conditions is incompletely studied and there is concern regarding long-term outcomes due to missing data. The only drug in this class with more extensive documentation is acetazolamide, but there is no approved label on this drug for use in OSA. Side-effects seem to be class-specific for drugs with a carbonic anhydrase inhibitory effect and proper mapping of safety should be performed over longer-term therapy. Excessive daytime sleepiness has not been shown to decrease after therapy. Cognitive symptoms are not uncommon for drugs with a carbonic anhydrase inhibitory effect, including topiramate and zonisamide. In addition, it remains that variability in the response to drug could be introduced by age, occupation, severity of the underlying condition and comorbidities. Putting these aspects together, the panel decided to make a recommendation for use under research conditions.

\section{Other considerations}

Drug therapy is familiar, acceptable to clinicians, and frequently preferred by patients. There is no prior information on the regulatory concerns that may be applied on the approval of a drug to be used in OSA, particularly with respect to relevant outcomes, efficacy and side-effects. In addition, the end-points that would justify a willingness to pay for this type of therapy in OSA are still uncertain.

\section{Suggestions for future research}

Large RCTs as part of conventional drug development programmes in various forms of OSA are warranted. Biomarkers useful for identification of candidates for drug therapy should be developed. The possibility to combine drug therapy with various forms of mechanical therapy in OSA should be explored. Finally, a better understanding of the effects of carbonic anhydrase inhibitors in comorbidities typical in OSA, such as cardiovascular and metabolic disorders and obesity, would be useful when exploring this form of therapy in OSA. The potential influence of drugs with a carbonic anhydrase inhibitory effect suggests that comorbidities in OSA, such as insulin resistance and diabetes, dyslipidaemia, systemic hypertension and cardiovascular disease should be specifically addressed in trials as there are experimental data suggesting that their appearance in patients with OSA may be influenced by the pathophysiological mechanism.

PICO 7: should positional therapy or CPAP be used for adult patients with position-dependent OSA? Conditional recommendation for either the intervention or the comparison, very low certainty of evidence.

Summary of the evidence

For PICOs 7 and 8, 1632 studies were originally identified, five of them for PICO 7, including 221 participants who were randomised to either positional therapy or CPAP (supplementary figures e7 and e12, supplementary tables e10 and e18) [78-84]. For the definition of positional OSA, all studies shared the criterion of the supine AHI to be at least twice as high as the nonsupine AHI. A relevant extent of 
nonsupine OSA was excluded, with corresponding AHI thresholds ranging from 5 events $\cdot \mathrm{h}^{-1}$ to 15 events $\cdot \mathrm{h}^{-1}$. All studies defined a minimum time of supine sleep, ranging from as low as $15 \mathrm{~min}$ to $1 \mathrm{~h}$ or $30 \%$ of total sleep time.

In one study $(\mathrm{n}=13)$, positional therapy consisted of a backpack with a soft ball inside [78]. A similar backpack-like device was used by Permut et al. [79] $(\mathrm{n}=38)$. Another study $(\mathrm{n}=20)$ applied the "tennis ball technique” (TBT) [81]. Mok et al. [83] $(\mathrm{n}=40)$ used the Night Shift device (vibratory device worn around the neck); BerRy et al. [84] $(\mathrm{n}=110)$ applied the NightBalance device (vibratory device worn around the chest).

All but one study [79] did not exclude patients with severe OSA. However, considering the mean baseline AHI, these studies were in the range of moderate OSA (AHI 15-30 events $\cdot \mathrm{h}^{-1}$ ). In the one study excluding an AHI $>30$ events $\cdot h^{-1}$ [79], the mean baseline AHI was 13 events $\cdot h^{-1}$. In most studies, the AHI was measured based on full-night in-lab PSG, except for one study applying home polygraphy [81] and another using a split-night PSG approach at baseline [78].

Both therapeutic modalities, CPAP and positional therapy, reduced the AHI effectively, while CPAP was slightly more effective than positional therapy (CPAP 4 events $\cdot h^{-1}$, positional therapy +5.79 events $\cdot h^{-1}$; 95\% CI 3.08-8.5 events $\cdot h^{-1}$ ). However, positional therapy was superior in terms of compliance (CPAP $4.9 \mathrm{~h}$ per night, positional therapy $+2.5 \mathrm{~h}$ per night; $95 \%$ CI $1.3-4.6 \mathrm{~h}$ per night). In this context, other studies found the TBT to be associated with low long-term compliance, mostly due to a lack of subjective comfort [85-87]. The mean sleep efficiency did not significantly differ between therapeutic modalities (CPAP 82.62\%, positional therapy $+1.85 \%$; 95\% CI $-1.54-5.23$ ). Sleepiness was assessed in three studies and 208 participants. It was measured using the ESS and showed no clinically relevant difference (CPAP 8.89, positional therapy +1.22 ; $95 \%$ CI $0.26-2.17$ ). Health-related quality of life was assessed in the same three studies and 170 participants [81, 83, 84] using the SF-36 and showed a mean value of 69.66 and was very similar on positional therapy, i.e. 0.6 points lower ( $-4.34-3.15$ points).

Side-effects were assessed in the same three out of five studies, including 170 participants. They were seldom seen and mild with both therapy forms and included skin irritation (CPAP and positional therapy), xerostomia (CPAP) and shoulder/neck pain (positional therapy). Two out of three studies [81, 84] found significantly fewer side-effects with positional therapy.

\section{Task force recommendation}

We suggest either positional therapy using vibratory devices or CPAP among adult patients with mild or moderate position-dependent OSA as defined by a supine AHI at least twice as high as the nonsupine AHI and no relevant nonsupine AHI $\left(<15\right.$ events $\cdot \mathrm{h}^{-1}$ ) (conditional recommendation for either the intervention or CPAP, very low certainty of evidence) (supplementary table e18).

\section{Justification of recommendation}

Based on five RCTs, the panel determined that in patients with position-dependent OSA, CPAP showed a slightly better effectiveness compared to positional therapy, while the compliance on CPAP is somewhat lower. Clinically relevant differences in symptomatic relief (ESS) and health-related quality of life were not observed. The recommendation was restricted to the positional therapy based on vibratory stimulation due to the limitation of adherence with other options.

\section{Other considerations}

It is difficult to compare the cost within Europe and coverage varies across patients/countries. Local differences of reimbursement still need to be investigated. Aside from positional therapy addressing the body position, there are two very small RCTs ( $n=10$ [80] and $n=14$ [82], respectively) in a general OSA population not explicitly specifying supine-dependent OSA. These focused on stabilising the head in a position without flexion or inclination and showed insufficient therapeutic efficacy. Thus, this therapeutic modality cannot be recommended. If the treatment is used, long-term efficacy and adherence require close follow-up by sleep specialists.

\section{Suggestions for future research}

More RCTs in OSA patients are warranted with different degrees of sleep apnoea, including patients with higher degree of disease severity. 
PICO 8: should positional therapy (intervention) or custom made dual-block MADs (control) be used for adult patients with adult position-dependent OSA?

Conditional recommendation for either the intervention or control, very low certainty of evidence.

Summary of the evidence

As mentioned earlier, for PICOs 7 and 8, 1632 studies were originally identified, but only one study was finally selected for PICO 8 [88, 89] (supplementary figure e7, supplementary tables e10 and e19; no meta-analysis was conducted). 99 adults with positional OSA were randomised to either positional therapy or MAD. The mean \pm SD age of the patients was $47.3 \pm 10.1$ and $49.2 \pm 10.2$ years, respectively. Only 58 patients completed the study. Under positional therapy, the AHI decreased from median (interquartile range (IQR)) 13.0 (9.7-18.5) events $\cdot \mathrm{h}^{-1}$ to 8.0 (5.1-12.9) events $\cdot \mathrm{h}^{-1}(\mathrm{p}<0.001)$, while in the MAD group the AHI decreased from median (IQR) $11.7(9.0-16.2)$ events $\cdot h^{-1}$ to $8.5(4.8-11.7)$ events $\cdot h^{-1}(p<0.001)$. No statistically significant difference between both therapies (no p-value) was given. Sleep efficiency assessed using PSG did not change significantly under positional therapy (from median (IQR) 92.0\% (84.0-95.5\%) to $91.0 \%(86.0-95.0 \%)$ ) or MAD (from 92.0\% (86.0-95.0\%) to $93.0 \%(87.0-96.0 \%)$ ). Quality of life assessed using the FOSQ-30 did not change significantly with either treatment. The ESS score decreased after positional therapy from median (IQR) 7.5 (4.0-12.0) to 6.0 (3.8-10.0), being not statistically significant. After MAD, the ESS did not change significantly (from median (IQR) 8.0 (4.0-13.0) to 8.0 (3.0-12.5)). No statistically significant differences between both therapies (no p-value) was given. Adherence, defined as device usage $\geqslant 4 \mathrm{~h}$ per night on $\geqslant 5$ days per week, showed a mean $68.9 \pm 37.7 \%$ for positional therapy and a mean $54.5 \pm 44.5 \%$ for the MAD (with temperature-measuring chip). The group difference was not statistically significant $(\mathrm{p}=0.086)$.

\section{Task force recommendation}

In patients with mild positional OSA, we suggest using either vibrational positional therapy or MAD (conditional recommendation for either the intervention or control, very low certainty of evidence) (supplementary table e19).

\section{Justification of recommendation}

Based on only one RCT, the panel determined that in patients with mild positional OSA vibrational positional therapy and MAD show similar effectiveness. However, more side-effects with MAD were found and adherence with the MAD was lower. For positional therapy, given different techniques and weak long-term adherence have to be taken into account. Patients' values and preferences may vary individually and may influence choice for one or the other therapy.

\section{Other considerations}

Physical limitations (discomfort or pain at the level of the shoulders or back) for positional therapy and bite and craniofacial changes and intermittent temporomandibular dysfunction for MAD have to be taken into account when considering long-term treatment.

Suggestions for future research

More RCTs in OSA patients are warranted with different degrees of sleep apnoea, including more severe patients. The type of positional OSA has to be taken into account when comparing future studies.

\section{Discussion}

In 2011, the ERS published a statement on non-CPAP therapies for the treatment of OSA [19]. It addressed both surgical and noninvasive procedures, including operations on soft and bony structures, orthodontic measures, especially mandibular advancement devices, and functional therapies. However, this statement required an update due to increasing numbers of publications on some of these options and the introduction of new approaches. Moreover, after a decade, an upgrade to a clinical guideline seemed necessary. Based on a first discussion of recent proceedings in the field, the panel decided to focus on eight PICO questions, representing approaches on various components of the pathophysiology.

- Due to the relevance of obesity, the role of the most frequently performed bariatric surgery was addressed.

- Maxillo-mandibular osteotomy was included to address the most effective interventional procedure to permanently increase the upper airway diameter.

- Mandibular advancement devices represent the most frequently used CPAP alternative and many scientific studies have been performed in recent years. Thus, evaluation of the current evidence seemed most important.

- Therapies addressing upper airway muscles have attracted interest including myofunctional therapy and HNS. 
- Finally, the role of positional therapy and pharmacological approaches are currently discussed intensively in the scientific community.

The PICOs selected seem to represent a huge variety of approaches. As the guideline had to focus on the most relevant topics, the panel decided against the inclusion of soft palate surgery due to a lack of substantial developments. Recently, MACKAY et al. [90] presented preliminary data on multilevel surgery showing substantial improvements of sleepiness associated with a limited reduction of the AHI. However, as the data had a preliminary character and were published after the time limit of the literature searches, this could not change the PICO selection. The multidimensional approach to OSA patients essentially includes education and weight reduction [91-93]. The relevance of dietary weight reduction was addressed in the previous statement, is beyond question and did not require re-evaluation [94]. Currently, the discussion on future options of alternative sleep apnoea treatment focuses on personalised selection or composition based on pathophysiological traits [95-97]. This may lead to multicomponent therapies, including various combinations of positive airway pressure, MADs or positional therapies [98-100] and may allow most effective and acceptable treatment for an individual patient to be found. New pharmaceutical agents may influence upper airway muscles [101], respiratory drive [102] or arousability. Thus, they might directly interact with the main pathophysiological factors. Although all these aspects are promising, they were beyond the topic of this guideline, as the evidence base is currently limited or preliminary.

In addition, several drugs address the problem of residual sleepiness despite optimal treatment of the underlying disease [103-105]. Unfortunately, these findings could not be included in this project as they do not focus on the causal treatment of the disease itself and major studies were published after the time limit of the literature searches. Despite high patient expectations and requirements for therapeutic alternatives, the task force still found a lack of sufficient evidence for several of the evaluated approaches, urging for more intensive scientific evaluation. For example, for gastric bypass surgery no RCTs are available that made a comparison with CPAP therapy. Interesting new approaches include combination therapies of various non-CPAP treatments to avoid CPAP or increase adherence [100]. Moreover, CPAP may be combined with an alternative option in order to reduce treatment pressure [98]. These combinations seem sound from a pathophysiological approach, addressing various traits. In addition, they are attractive for patients who want to avoid CPAP therapy. However, the scientific evidence on these concepts is still on a basic level so that they could not be included in this guideline.

The comparison of CPAP and custom made dual-block advancement devices showed the highest level of evidence including 13 RCTs [32, 36-41, 44, 46, 48-51]. It showed superiority of CPAP versus MAD. However, this focused mainly on the reduction of the AHI, while effects on patient-related outcome parameters were equal. The panel is aware that the relevance of the AHI is decreasing in sleep medicine [11]. However, it is still the widest used biomarker of breathing disturbances, especially focusing on cardiometabolic consequences. The evolving relevance of patient-related outcome measures has led to the differentiated recommendation. The different effect on AHI and systolic night-time blood pressure might be most important for patients with severe sleep apnoea as measured by the AHI. It should also be taken into account that one of the two studies included in this analysis excluded seriously ill patients with an urgent need of OSA treatment $[48,51]$.

Based on very low certainty of the evidence, the panel decided on a conditional recommendation against HNS as a first-line treatment for OSA patients in general. However, based on the data analysed, it can be used in symptomatic OSA patients who have failed or have not tolerated CPAP treatment, but the indication should follow the inclusion criteria of the STAR trial [20]. Similarly, MMO can be an alternative for patients experiencing CPAP failure [106]. Finally, despite very low certainty of evidence, patients with mild to moderate position-dependent OSA can be treated with vibratory positional therapy as compared to CPAP or as compared to mandibular advancement [83, 84, 88, 89].

It might have been desirable to differentiate clearly between first- and second-line therapies in the recommendations. However, such a clear separation was only possible for a minority of topics.

Importantly, there would be a high risk of increasing health inequity if all treatment approaches investigated here were to be recommended. The high costs of some therapies, e.g. HNS, different reimbursement rules of national healthcare systems, or heterogeneous availability due to lack of expertise do not allow all patients to get similar access to effective therapies.

In summary, there is still a lack of high scientific evidence on non-CPAP treatment options for OSA. However, substantial progress has been made regarding custom-made dual-block MADs, positional therapy 
and HNS, while pharmaceutical therapy and myofunctional therapy currently do not allow for a positive recommendation.

Provenance: Submitted article, peer reviewed.

Acknowledgements: We thank Carla Miltz (Bethanien Hospital, Clinic of Pneumology and Allergology, Center for Sleep Medicine and Respiratory Care, Solingen, Germany) for her assistance in coordinating the task force and managing the manuscript. We thank Barbara Johnson and Clare Williams from the European Lung Foundation (Sheffield, UK) for their support in coordinating patient involvement. In addition to the mentioned patient representatives in the author list, we would like to thank Mark de Quidt, the representative of the Sleep Apnea Association (Flanders, Belgium), who also delivered valuable input.

This ERS guideline was endorsed by the ERS Executive Committee on 10 September 2021.

The guidelines published by the European Respiratory Society (ERS) incorporate data obtained from a comprehensive and systematic literature review of the most recent studies available at the time. Health professionals are encouraged to take the guidelines into account in their clinical practice. However, the recommendations issued by this guideline may not be appropriate for use in all situations. It is the individual responsibility of health professionals to consult other sources of relevant information, to make appropriate and accurate decisions in consideration of each patient's health condition and in consultation with that patient and the patient's caregiver where appropriate and/or necessary, and to verify rules and regulations applicable to drugs and devices at the time of prescription.

Conflicts of Interest: W. Randerath reports personal fees received from Weinmann, Heinen \& Löwenstein, Resmed, Inspire, Philips Respironics, and Bioprojet, outside the submitted work. J. Verbraecken reports receiving payments to institution for lectures, presentations, speakers bureaus, manuscript writing or educational events from SomnoMed and Inspire Medical Systems, outside the submitted work. Participation on a Data Safety Monitoring Board or Advisory Board for ResMed Narval, payments to institution, outside the submitted work. C.A.L. de Raaff has nothing to disclose. J. Heder reports grants received from ResMed, outside the submitted work. Lecture fees from Bayer Pharma and Jazz Pharmaceuticals outside the submitted work. Patent filed and granted for Pharmacological therapy in OSA. Participation on a data safety monitoring board or advisory board for DSMB. S. Herkenrath has nothing to disclose. W. Hohenhorst has nothing to disclose. T. Jakob has nothing to disclose. O. Marrone has nothing to disclose. M. Marklund has nothing to disclose. W.T. McNicholas has nothing to disclose. R.L. Morgan has nothing to disclose. J-L. Pépin reports grants and research funds from (payments made to the institutions) Air Liquide Foundation, Agiradom, AstraZeneca, Fisher and Paykel, Mutualia, Philips, Resmed and Vitalaire, outside the submitted work. Consulting fees from: Agiradom, AstraZeneca, Boehringer Ingelheim, Jazz pharmaceutical, Night Balance, Philips, Resmed, and Sefam, outside the submitted work. S. Schiza has nothing to disclose. N. Skoetz reports support for the present manuscript from the European Respiratory Society. Personal payments received from Cochrane outside the submitted work. D. Smyth has nothing to disclose. J. Steier reports receiving grants from the British Lung Foundation, outside the submitted work. Payments of honoraria received from Jazz Pharmaceuticals and Sanofi. Named inventor on pending patent WO2016124739A1. President of the British Sleep Society. T. Tonia acts as an ERS methodologist. W. Trzepizur has nothing to disclose. P-H. van Mechelen has nothing to disclose. P. Wijkstra has nothing to disclose.

Support statement: The participants of the project received funding for travel and meetings from the European Respiratory Society (no TF-2018-01). Funding information for this article has been deposited with the Crossref Funder Registry.

\section{References}

$1 \quad$ Sullivan CE, Issa FG, Berthon-Jones M, et al. Reversal of obstructive sleep apnoea by continuous positive airway pressure applied through the nares. Lancet 1981; 1: 862-865.

2 Abud R, Salgueiro M, Drake L, et al. Efficacy of continuous positive airway pressure (CPAP) preventing type 2 diabetes mellitus in patients with obstructive sleep apnea hypopnea syndrome (OSAHS) and insulin resistance: a systematic review and meta-analysis. Sleep Med 2019; 62: 14-21.

3 Khan SU, Duran CA, Rahman H, et al. A meta-analysis of continuous positive airway pressure therapy in prevention of cardiovascular events in patients with obstructive sleep apnoea. Eur Heart J 2018; 39: 2291-2297.

4 Labarca G, Saavedra D, Dreyse J, et al. Efficacy of CPAP for improvements in sleepiness, cognition, mood, and quality of life in elderly patients with OSA: systematic review and meta-analysis of randomized controlled trials. Chest 2020; 158: 751-764. 
5 stroke in patients with moderate to severe obstructive sleep apnea: an updated systematic review and meta-analysis. Sleep Med Rev 2020; 54: 101354. Olaithe M, Bucks RS. Executive dysfunction in OSA before and after treatment: a meta-analysis. Sleep 2013; 36: 1297-1305.

7 Tregear S, Reston J, Schoelles K, et al. Continuous positive airway pressure reduces risk of motor vehicle crash among drivers with obstructive sleep apnea: systematic review and meta-analysis. Sleep 2010; 33: 1373-1380.

8 Wang ML, Wang C, Tuo M, et al. Cognitive effects of treating obstructive sleep apnea: a meta-analysis of randomized controlled trials. J Alzheimers Dis 2020; 75: 705-715.

9 Eckert DJ, White DP, Jordan AS, et al. Defining phenotypic causes of obstructive sleep apnea. Identification of novel therapeutic targets. Am J Respir Crit Care Med 2013; 188: 996-1004.

10 Wellman A, Eckert DJ, Jordan AS, et al. A method for measuring and modeling the physiological traits causing obstructive sleep apnea. J Appl Physiol 2011; 110: 1627-1637.

11 Pevernagie DA, Gnidovec-Strazisar B, Grote L, et al. On the rise and fall of the apnea-hypopnea index: a historical review and critical appraisal. J Sleep Res 2020; 29: e13066.

12 Dong JY, Zhang YH, Qin LQ. Obstructive sleep apnea and cardiovascular risk: meta-analysis of prospective cohort studies. Atherosclerosis 2013; 229: 489-495.

13 Fu Y, Xia Y, Yi H, et al. Meta-analysis of all-cause and cardiovascular mortality in obstructive sleep apnea with or without continuous positive airway pressure treatment. Sleep Breath 2017; 21: 181-189.

14 Marin JM, Carrizo SJ, Vicente E, et al. Long-term cardiovascular outcomes in men with obstructive sleep apnoea-hypopnoea with or without treatment with continuous positive airway pressure: an observational study. Lancet 2005; 365: 1046-1053.

15 Abma IL, Rovers MM, IJff M, et al. Does the Patient-Reported Apnea Questionnaire (PRAQ) increase patient-centredness in the daily practice of sleep centres? A mixed-methods study. BMJ Open 2019; 9: e025963.

Mehta N, Mandavia R, Patel A, et al. Patient-reported outcome measure for obstructive sleep apnea: symptoms, tiredness, alertness, mood and psychosocial questionnaire: preliminary results. J Sleep Res 2020; 29: e12960.

17 McArdle N, Devereux G, Heidarnejad H, et al. Long-term use of CPAP therapy for sleep apnea/hypopnea syndrome. Am J Respir Crit Care Med 1999; 159: 1108-1114.

18 McEvoy RD, Antic NA, Heeley E, et al. CPAP for prevention of cardiovascular events in obstructive sleep apnea. N Engl J Med 2016; 375: 919-931.

19 Randerath WJ, Verbraecken J, Andreas S, et al. Non-CPAP therapies in obstructive sleep apnoea. Eur Respir J 2011; 37: 1000-1028.

20 Strollo PJ Jr, Soose RJ, Maurer JT, et al. Upper-airway stimulation for obstructive sleep apnea. N Engl J Med 2014; 370: 139-149.

21 Van de Heyning PH, Badr MS, Baskin JZ, et al. Implanted upper airway stimulation device for obstructive sleep apnea. Laryngoscope 2012; 122: 1626-1633.

22 de Vries GE, Hoekema A, Vermeulen KM, et al. Clinical- and cost-effectiveness of a mandibular advancement device versus continuous positive airway pressure in moderate obstructive sleep apnea. J Clin Sleep Med 2019; 15: 1477-1485.

23 Yingjuan M, Siang WH, Leong Alvin TK, et al. Positional therapy for positional obstructive sleep apnea. Sleep Med Clin 2020; 15: 261-275.

European Respiratory Society (ERS). ERS Task Forces for the Development of Clinical Practice Guidelines, Statements and Technical Standards - Guidance 2021. 2021. https://www.ersnet.org/wp-content/uploads/ 2021/01/TF-Guidelines-and-application-form_Feb2021_Final-2.pdf/

作 JPT, Thomas J, Chandler J, et al., eds. Cochrane Handbook for Systematic Reviews of Interventions version 6.0 (updated July 2019). 2019. https://training.cochrane.org/handbook/ Balshem H, Helfand M, Schünemann HJ, et al. GRADE guidelines: 3. Rating the quality of evidence. J Clin Epidemiol 2011; 64: 401-406.

27 Joosten SA, Khoo JK, Edwards BA, et al. Improvement in obstructive sleep apnea with weight loss is dependent on body position during sleep. Sleep 2017; 40: zsx047.

28 Dixon JB, Schachter LM, O'Brien PE, et al. Surgical vs conventional therapy for weight loss treatment of obstructive sleep apnea: a randomized controlled trial. JAMA 2012; 308: 1142-1149.

29 Peppard PE, Young T, Palta M, et al. Longitudinal study of moderate weight change and sleep-disordered breathing. JAMA 2000; 284: 3015-3021.

30 Newman AB, Foster G, Givelber R, et al. Progression and regression of sleep-disordered breathing with changes in weight: the Sleep Heart Health Study. Arch Intern Med 2005; 165: 2408-2413. 
Hudgel DW, Patel SR, Ahasic AM, et al. The role of weight management in the treatment of adult obstructive sleep apnea. An official American Thoracic Society clinical practice guideline. Am J Respir Crit Care Med 2018; 198: e70-e87.

Aarab G, Lobbezoo F, Hamburger HL, et al. Oral appliance therapy versus nasal continuous positive airway pressure in obstructive sleep apnea: a randomized, placebo-controlled trial. Respiration 2011; 81: 411-419.

Aarab G, Lobbezoo F, Heymans MW, et al. Long-term follow-up of a randomized controlled trial of oral appliance therapy in obstructive sleep apnea. Respiration 2011; 82: 162-168.

Aarab G, Nikolopoulou M, Ahlberg J, et al. Oral appliance therapy versus nasal continuous positive airway pressure in obstructive sleep apnea: a randomized, placebo-controlled trial on psychological distress. Clin Oral Investig 2017; 21: 2371-2378.

Nikolopoulou M, Byraki A, Ahlberg J, et al. Oral appliance therapy versus nasal continuous positive airway pressure in obstructive sleep apnoea syndrome: a randomised, placebo-controlled trial on self-reported symptoms of common sleep disorders and sleep-related problems. J Oral Rehabil 2017; 44: 452-460.

Barnes M, McEvoy RD, Banks S, et al. Efficacy of positive airway pressure and oral appliance in mild to moderate obstructive sleep apnea. Am J Respir Crit Care Med 2004; 170: 656-664.

Dal-Fabbro C, Garbuio S, D'Almeida V, et al. Mandibular advancement device and CPAP upon cardiovascular parameters in OSA. Sleep Breath 2014; 18: 749-759.

de Vries GE, Hoekema A, Claessen J, et al. Long-term objective adherence to mandibular advancement device therapy versus continuous positive airway pressure in patients with moderate obstructive sleep apnea. J Clin Sleep Med 2019; 15: 1655-1663.

El-Solh AA, Homish GG, Ditursi G, et al. A randomized crossover trial evaluating continuous positive airway pressure versus mandibular advancement device on health outcomes in veterans with posttraumatic stress disorder. J Clin Sleep Med 2017; 13: 1327-1335.

Ferguson KA, Ono T, Lowe AA, et al. A short-term controlled trial of an adjustable oral appliance for the treatment of mild to moderate obstructive sleep apnoea. Thorax 1997; 52: 362-368.

Gagnadoux F, Fleury B, Vielle B, et al. Titrated mandibular advancement versus positive airway pressure for sleep apnoea. Eur Respir J 2009; 34: 914-920.

Trzepizur W, Gagnadoux F, Abraham P, et al. Microvascular endothelial function in obstructive sleep apnea: impact of continuous positive airway pressure and mandibular advancement. Sleep Med 2009; 10: 746-752.

Glos M, Fietze I, Schobel C, et al. Therapy of OSA by mandibular advancement device therapy-effects of a crossover trial of SomnoDent and CPAP on respiration and daytime cardiac autonomic function. $J$ Sleep Res 2016; 25: Suppl. 1, P249.

Glos M, Penzel T, Schoebel C, et al. Comparison of effects of OSA treatment by MAD and by CPAP on cardiac autonomic function during daytime. Sleep Breath 2016; 20: 635-646.

Doff MH, Veldhuis SK, Hoekema A, et al. Long-term oral appliance therapy in obstructive sleep apnea syndrome: a controlled study on temporomandibular side effects. Clin Oral Investig 2012; 16: 689-697.

Hoekema A, Stegenga B, Wijkstra PJ, et al. Obstructive sleep apnea therapy. J Dent Res 2008; 87: 882-887.

Doff $\mathrm{MH}$, Hoekema A, Wijkstra PJ, et al. Oral appliance versus continuous positive airway pressure in obstructive sleep apnea syndrome: a 2-year follow-up. Sleep 2013; 36: 1289-1296.

Phillips CL, Grunstein RR, Darendeliler MA, et al. Health outcomes of continuous positive airway pressure versus oral appliance treatment for obstructive sleep apnea: a randomized controlled trial. Am J Respir Crit Care Med 2013; 187: 879-887.

Schütz TC, Cunha TC, Moura-Guimaraes T, et al. Comparison of the effects of continuous positive airway pressure, oral appliance and exercise training in obstructive sleep apnea syndrome. Clinics 2013; 68: 1168-1174.

0 Tan YK, L'Estrange PR, Luo YM, et al. Mandibular advancement splints and continuous positive airway pressure in patients with obstructive sleep apnoea: a randomized cross-over trial. Eur J Orthod 2002; 24: 239-249.

1 Yamamoto U, Nishizaka $\mathrm{M}$, Tsuda $\mathrm{H}$, et al. Crossover comparison between CPAP and mandibular advancement device with adherence monitor about the effects on endothelial function, blood pressure and symptoms in patients with obstructive sleep apnea. Heart Vessels 2019; 34: 1692-1702.

Barnes M, Collins AL, Smart K, et al. Short term outcomes for obstructive sleep apnoea patients treated with hypoglossal nerve stimulation. J Sleep Res 2014; 23: 66.

Pengo MF, Xiao S, Ratneswaran C, et al. Randomised sham-controlled trial of transcutaneous electrical stimulation in obstructive sleep apnoea. Thorax 2016; 71: 923-931.

Smart K, O'Donoghue F, Worsnop C, et al. Short term outcomes for obstructive sleep apnoea patients treated with hypoglossal nerve stimulation. Sleep Biol Rhythms 2013; 11: Suppl. S2, 68-69.

Woodson BT, Gillespie MB, Soose RJ, et al. Randomized controlled withdrawal study of upper airway stimulation on OSA: short- and long-term effect. Otolaryngol Head Neck Surg 2014; 151: 880-887.

Dedhia RC, Quyyumi AA, Park J, et al. Cardiovascular endpoints for obstructive sleep apnea with twelfth cranial nerve stimulation (CARDIOSA-12): rationale and methods. Laryngoscope 2018; 128: 2635-2643. 
Inspire Medical Systems. Inspire ${ }^{\circledR}$ Upper Airway Stimulation System (RCT). https://clinicaltrials.gov/ct2/show/ NCT02675816 Date last updated: 11 August 2016.

ImThera Medical. Targeted Hypoglossal Neurostimulation Study \#3 (THN3). https://clinicaltrials.gov/ct2/ show/NCT02263859/ Date last updated: 9 April 2021.

Ratneswaran D, Guni A, Pengo MF, et al. Electrical stimulation as a therapeutic approach in obstructive sleep apnea - a meta-analysis. Sleep Breath 2021; 25: 207-218.

Diaferia G, Badke L, Santos-Silva R, et al. Effect of speech therapy as adjunct treatment to continuous positive airway pressure on the quality of life of patients with obstructive sleep apnea. Sleep Med 2013; 14 628-635.

Diaferia G, Santos-Silva R, Truksinas E, et al. Myofunctional therapy improves adherence to continuous positive airway pressure treatment. Sleep Breath 2017; 21: 387-395.

Guimarães KC, Drager LF, Genta PR, et al. Effects of oropharyngeal exercises on patients with moderate obstructive sleep apnea syndrome. Am J Respir Crit Care Med 2009; 179: 962-966.

leto V, Kayamori F, Montes MI, et al. Effects of oropharyngeal exercises on snoring: a randomized trial. Chest 2015; 148: 683-691.

Neumannova K, Hobzova M, Sova M, et al. Pulmonary rehabilitation and oropharyngeal exercises as an adjunct therapy in obstructive sleep apnea: a randomized controlled trial. Sleep Med 2018; 52: 92-97.

Puhan MA, Suarez A, Lo Cascio C, et al. Didgeridoo playing as alternative treatment for obstructive sleep apnoea syndrome: randomised controlled trial. BMJ 2006; 332: 266-270.

Randerath WJ, Galetke W, Domanski U, et al. Tongue-muscle training by intraoral electrical neurostimulation in patients with obstructive sleep apnea. Sleep 2004; 27: 254-259.

Torres-Castro R, Vilaró J, Martí J-D, et al. Effects of a combined community exercise program in obstructive sleep apnea syndrome: a randomized clinical trial. J Clin Med 2019; 8: 361.

Atilgan E, Kunter E, Algun ZC. Are oropharyngeal exercises effective in obstructive sleep apnea syndrome? J Back Musculoskelet Rehabil 2020; 33: 209-216.

Lin HY, Chang CJ, Chiang CC, et al. Effects of a comprehensive physical therapy on moderate and severe obstructive sleep apnea - a preliminary randomized controlled trial. J Formos Med Assoc 2020; 119: 1781-1790.

Vicini C, Dallan I, Campanini A, et al. Surgery vs ventilation in adult severe obstructive sleep apnea syndrome. Am J Otolaryngol 2010; 31: 14-20.

Eskandari D, Zou D, Karimi M, et al. Zonisamide reduces obstructive sleep apnoea: a randomised placebo-controlled study. Eur Respir J 2014; 44: 140-149.

Latshang TD, Nussbaumer-Ochsner Y, Henn RM, et al. Effect of acetazolamide and autoCPAP therapy on breathing disturbances among patients with obstructive sleep apnea syndrome who travel to altitude: a randomized controlled trial. JAMA 2012; 308: 2390-2398.

Nussbaumer-Ochsner Y, Latshang TD, Ulrich S, et al. Patients with obstructive sleep apnea syndrome benefit from acetazolamide during an altitude sojourn: a randomized, placebo-controlled, double-blind trial. Chest 2012; 141: 131-138.

Latshang TD, Kaufmann B, Nussbaumer-Ochsner Y, et al. Patients with obstructive sleep apnea have cardiac repolarization disturbances when travelling to altitude: randomized, placebo-controlled trial of acetazolamide. Sleep 2016; 39: 1631-1637.

Ulrich S, Nussbaumer-Ochsner Y, Vasic I, et al. Cerebral oxygenation in patients with OSA: effects of hypoxia at altitude and impact of acetazolamide. Chest 2014; 146: 299-308.

Whyte KF, Gould GA, Airlie MA, et al. Role of protriptyline and acetazolamide in the sleep apnea/hypopnea syndrome. Sleep 1988; 11: 463-472.

Winslow DH, Bowden $\mathrm{CH}$, DiDonato KP, et al. A randomized, double-blind, placebo-controlled study of an oral, extended-release formulation of phentermine/topiramate for the treatment of obstructive sleep apnea in obese adults. Sleep 2012; 35: 1529-1539.

Jokic R, Klimaszewski A, Crossley M, et al. Positional treatment vs continuous positive airway pressure in patients with positional obstructive sleep apnea syndrome. Chest 1999; 115: 771-781.

Permut I, Diaz-Abad M, Chatila W, et al. Comparison of positional therapy to CPAP in patients with positional obstructive sleep apnea. J Clin Sleep Med 2010; 6: 238-243.

Skinner MA, Kingshott RN, Jones DR, et al. Lack of efficacy for a cervicomandibular support collar in the management of obstructive sleep apnea. Chest 2004; 125: 118-126.

Skinner MA, Kingshott RN, Filsell S, et al. Efficacy of the 'tennis ball technique' versus nCPAP in the management of position-dependent obstructive sleep apnoea syndrome. Respirology 2008; 13: 708-715.

Skinner MA, Kingshott RN, Jones DR, et al. Elevated posture for the management of obstructive sleep apnea. Sleep Breath 2004; 8: 193-200.

Mok Y, Tan A, Hsu PP, et al. Comparing treatment effects of a convenient vibratory positional device to CPAP in positional OSA: a crossover randomised controlled trial. Thorax 2020; 75: 331-337. 
Berry RB, Uhles ML, Abaluck BK, et al. NightBalance sleep position treatment device versus auto-adjusting positive airway pressure for treatment of positional obstructive sleep apnea. J Clin Sleep Med 2019; 15: 947-956.

Bignold JJ, Deans-Costi G, Goldsworthy MR, et al. Poor long-term patient compliance with the tennis ball technique for treating positional obstructive sleep apnea. J Clin Sleep Med 2009; 5: 428-430.

Oksenberg A, Silverberg D, Offenbach D, et al. Positional therapy for obstructive sleep apnea patients: a 6-month follow-up study. Laryngoscope 2006; 116: 1995-2000.

Eijsvogel MM, Ubbink R, Dekker J, et al. Sleep position trainer versus tennis ball technique in positional obstructive sleep apnea syndrome. J Clin Sleep Med 2015; 11: 139-147.

de Ruiter MHT, Benoist LBL, de Vries N, et al. Durability of treatment effects of the Sleep Position Trainer versus oral appliance therapy in positional OSA: 12-month follow-up of a randomized controlled trial. Sleep Breath 2018; 22: 441-450.

Benoist L, de Ruiter M, de Lange J, et al. A randomized, controlled trial of positional therapy versus oral appliance therapy for position-dependent sleep apnea. Sleep Med 2017; 34: 109-117.

Mackay S, Carney AS, Catcheside PG, et al. Effect of multilevel upper airway surgery vs medical management on the apnea-hypopnea index and patient-reported daytime sleepiness among patients with moderate or severe obstructive sleep apnea: the SAMS randomized clinical trial. JAMA 2020; 324: 1168-1179. Wozniak DR, Lasserson TJ, Smith I. Educational, supportive and behavioural interventions to improve usage of continuous positive airway pressure machines in adults with obstructive sleep apnoea. Cochrane Database Syst Rev 2014; 1: CD007736.

Georgoulis M, Yiannakouris N, Kechribari I, et al. The effectiveness of a weight-loss Mediterranean diet/ lifestyle intervention in the management of obstructive sleep apnea: results of the "MIMOSA" randomized clinical trial. Clin Nutr 2021; 40: 850-859.

de Melo CM, Dos Santos Quaresma MVL, Del Re MP, et al. One-month of a low-energy diet, with no additional effect of high-protein, reduces obstructive sleep apnea severity and improve metabolic parameters in obese males. Clin Nutr ESPEN 2021; 42: 82-89.

Lindberg E, Elmasry A, Gislason T, et al. Evolution of sleep apnea syndrome in sleepy snorers: a population-based prospective study. Am J Respir Crit Care Med 1999; 159: 2024-2027.

Edwards BA, Andara C, Landry S, et al. Upper-airway collapsibility and loop gain predict the response to oral appliance therapy in patients with obstructive sleep apnea. Am J Respir Crit Care Med 2016; 194: 1413-1422.

Deacon NL, Jen R, Li Y, et al. Treatment of obstructive sleep apnea. Prospects for personalized combined modality therapy. Ann Am Thorac Soc 2016; 13: 101-108.

Op de Beeck S, Wellman A, Dieltjens M, et al. Endotypic mechanisms of successful hypoglossal nerve stimulation for obstructive sleep apnea. Am J Respir Crit Care Med 2021; 203: 746-755.

El-Solh AA, Moitheennazima B, Akinnusi ME, et al. Combined oral appliance and positive airway pressure therapy for obstructive sleep apnea: a pilot study. Sleep Breath 2011; 15: 203-208.

Tong BK, Tran C, Ricciardiello A, et al. CPAP combined with oral appliance therapy reduces CPAP requirements and pharyngeal pressure swings in obstructive sleep apnea. J Appl Physiol 2020; 129: 1085-1091.

Dieltjens M, Vroegop AV, Verbruggen AE, et al. A promising concept of combination therapy for positional obstructive sleep apnea. Sleep Breath 2015; 19: 637-644.

Taranto-Montemurro L, Messineo L, Sands SA, et al. The combination of atomoxetine and oxybutynin greatly reduces obstructive sleep apnea severity. A randomized, placebo-controlled, double-blind crossover trial. Am J Respir Crit Care Med 2019; 199: 1267-1276.

Lim R, Messineo L, Grunstein RR, et al. The noradrenergic agent reboxetine plus the antimuscarinic hyoscine butylbromide reduces sleep apnoea severity: a double-blind, placebo-controlled, randomised crossover trial. J Physiol 2021; 599: 4183-4195.

03 Strollo PJ Jr, Hedner J, Collop N, et al. Solriamfetol for the treatment of excessive sleepiness in OSA: a placebo-controlled randomized withdrawal study. Chest 2019; 155: 364-374.

4 Dauvilliers Y, Verbraecken J, Partinen M, et al. Pitolisant for daytime sleepiness in patients with obstructive sleep apnea who refuse continuous positive airway pressure treatment. A randomized trial. Am J Respir Crit Care Med 2020; 201: 1135-1145.

05 Schweitzer PK, Rosenberg R, Zammit GK, et al. Solriamfetol for excessive sleepiness in obstructive sleep apnea (TONES 3). A randomized controlled trial. Am J Respir Crit Care Med 2019; 199: 1421-1431.

Jalbert $\mathrm{F}$, Lacassagne L, Bessard J, et al. Orthèse d'avancée mandibulaire ou ostéotomie maxillo-mandibulaire pour le traitement des syndromes d'apnées obstructives du sommeil sévères refusant la PPC. [Oral appliances or maxillomandibular advancement osteotomy for severe obstructive sleep apnoea in patients refusing CPAP]. Rev Stomatol Chir Maxillofac 2012; 113: 19-26. 